\title{
SILICON-CONTAINING POLY(IMIDE-AMIDES) DERIVED FROM ALIPHATIC DIACIDS WITH NAPHATHALIMIDYL SIDE GROUPS. SYNTHESIS AND THERMAL STUDIES
}

\author{
L.H. TAGLE, C.A. TERRAZA, A. TUNDIDOR-CAMBA, F.A. LARA
}

Pontificia Universidad Católica de Chile, Facultad de Química, P.O. Box 306, Santiago, Chile

(Received: August 5, 2013 - Accepted: November 19, 2013)

\begin{abstract}
Poly(imide-amides) (PIAs) were obtained from aspartic and glutamic acids containing both a 1,8-naphthlimidyl side group and the diamine bis(4-aminophenyl) diphenylsilane, according to the Yamazaki method and characterized by elemental analysis, optical activity, IR and ${ }^{1} \mathrm{H},{ }^{13} \mathrm{C}$ and ${ }^{29} \mathrm{Si}$ NMR spectroscopy. PIAs were soluble at room temperature in common aprotic polar solvents (DMSO, DMAc, DMF, NMP) and in other of lower polarity but low boiling point (CHCl, THF) after heating. The inherent viscosity values were low, which was indicative of low molecular weight species of oligomeric nature. The $\mathrm{Tg}$ values were relatively high considering the aliphatic nature of the diacids and the bulky side groups, which cause an impediment to the rotation. It is possible to suppose a weak hydrogen bond interaction between the $\mathrm{NH}$ groups of the amide and the carbonyl groups of the imide. When the Tg of both PIAs was compared, it was possible to see a decrease when the main chain was increased in one $-\mathrm{CH}_{2}$ - group. PIAs were not thermostable but the TDT values were relatively high considering the aliphatic nature of the diacid moiety, being PIA-As more thermostable than PIA-Gl with a longer aliphatic chain. Both PIAs showed a similar optical behavior and high transparence at $450 \mathrm{~nm}$, which can be explained by the aliphatic character of the diacid moiety.
\end{abstract}

Keywords: poly(imide-amides), silicon-containing polymers, thermal properties

\section{INTRODUCTION}

Aromatic poly(amides) are condensation polymers obtained from dicarboxylic acids and diamines, which have excellent thermal and mechanical properties. ${ }^{1-3}$ However, aromatic poly(amides) are normally insoluble in common organic solvents, show high Tg values and are thermostables. The insolubility has been attributed to dipole-dipole interactions between the polymeric chains caused by hydrogen bonds. ${ }^{4}$

There are several structural changes in order to obtain good properties for the processing of poly(amides), such as the incorporation of flexible units, meta-substituted aromatic rings, heteroatoms like $\mathrm{Si}$ at the main chain and bulky side groups, which avoid the interactions between the chains. ${ }^{5-7}$ All of these possibilities have as objective to increase the solubility, to decrease the $\mathrm{Tg}$ values and to maintain the thermal stability. ${ }^{8}$ The Si atoms in the main chain and bonded to four organic groups can to improve the solubility in organic polar solvents due to the polarity of the $\mathrm{Si}-\mathrm{C}$ bond caused by the difference of electronegativity. In this sense several works have been described containing $\mathrm{Si}$ atoms in the main chain showing an increase of the solubility but maintaining good thermal stability. ${ }^{9}$

In this work we describe the synthesis of poly(imide-amides) derived from two aliphatic diacids: aspartic and glutamic, bonded to a naphthalimidyl side group, and a wholly aromatic diamine containing a $\mathrm{Si}$ atom. Polymers were obtained by the Yamazaki procedure and were characterized by spectroscopic methods and the thermal properties were determined..$^{10}$ The results were related to the polymeric structure.

\section{EXPERIMENTAL PART}

\section{Materials}

The diacids 2-amino-butanedioic (aspartic acid), 2-amino-pentanedioic (glutamic acid) and 1,8-naphthalic anhydride were obtained from Aldrich Chemical (Milwaukee, WI). Reagents and solvents were purchased commercially as analytical-grade and their purity checked by ${ }^{1} \mathrm{H}$ and ${ }^{13} \mathrm{C}$ NMR spectroscopy.

\section{Instrumentation}

The IR spectra ( $\mathrm{KBr}$ pellets) were recorded on a Perkin-Elmer (Fremont CA) 1310 spectrophotometer over the range of $450-4000 \mathrm{~cm}^{-1} .{ }^{1} \mathrm{H},{ }^{13} \mathrm{C}$ and ${ }^{29} \mathrm{Si}$ NMR spectra were carried out on a $400 \mathrm{MHz}$ instrument (Bruker AC-200) using DMSO- $d_{6}, \mathrm{CDCl}_{3}$ or acetone- $d_{6}$ as solvents and TMS as the internal standard. Viscosimetric measurements were made in a Desreux-Bischof type dilution viscosimeter at $25^{\circ} \mathrm{C}(\mathrm{c}=0.3 \mathrm{~g} / \mathrm{dL})$. Thermal glass transition $(\mathrm{Tg})$ values were obtained with a Mettler-Toledo (Greifensee, Switzerland) DSC

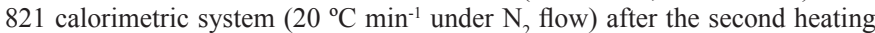
run. Thermogravimetric analyses were carried out in a Mettler (Switzerland)
TA-3000 calorimetric system equipped with a TC-10A processor, and a TG-50 thermobalance with a Mettler MT5 microbalance. Samples of 6-10 mg were placed in a platinum sample holder and the thermogravimetric measurements were carried out between $30^{\circ} \mathrm{C}$ and $800^{\circ} \mathrm{C}$ with a heating rate of $20^{\circ} \mathrm{C} \mathrm{min}$ ${ }^{1}$ under $\mathrm{N}_{2}$ flow. Specific rotations were measured in an Optical Activity Automatic polarimeter, Model AA-5 at $25{ }^{\circ} \mathrm{C}$ in $\mathrm{N}, \mathrm{N}$-dimethylformamide $(\mathrm{DMF})(\mathrm{c}=50 \mathrm{mg} / \mathrm{mL})$. The UV-visible optical transmission spectra were obtained on a UV-3101 UV-vis-NIR scanning spectrophotometer (Shimadzu) at room temperature, using solutions of $N$-methyl-2-pyrrolidone (NMP) $(\mathrm{c}=0.5$ $\mathrm{g} / \mathrm{L}$ ). Elemental analyses were made on a Fisons EA 1108-CHNS-O equipment. Monomers

The diacids 1,8-naphthalimidyl-aspartic (1,8-naphthalimidyl-butanedioic) (DA-As) and 1,8-naphthalimidyl-glutamic (2-(1,8-naphthalimidyl)pentanedioic) (DA-GI) were obtained according to the following general procedure $^{11}$ : $10 \mathrm{mmol}$ of 1,8-naphthyl anhydride are mixed with $15 \mathrm{mmol}$ of the amino acid respective and $20 \mathrm{~mL}$ of DMF and the mixture refluxed by one hour. After this time the DMF was distilled and the residue poured in $40 \mathrm{~mL}$ of water and $10 \mathrm{~mL}$ of $\mathrm{HCl}$. The solid is filtered, washed with dilute $\mathrm{HCl}$ and then with water several times, dried under vacuum until constant weight and characterized.

DA-As. Yield: $70 \%$. [a] ${ }_{589}^{17}(\mathrm{DMF})=-4\left(\mathrm{deg}^{-1} \mathrm{~g}^{-1} \mathrm{~cm}^{3}\right)$. M.p.: $232-234{ }^{\circ} \mathrm{C}$. IR (KBr) (n) (cm-1): 3468 (O-H), 3078 (C-H arom.), 2943 (C-H aliph.), 1765 $(\mathrm{C}=\mathrm{O}$ imide $), 1731(\mathrm{C}=\mathrm{O}$ acid $), 1694,1656(\mathrm{C}=\mathrm{O}$ imide $), 1588,1514(\mathrm{C}=\mathrm{C}$ arom.), 1438 (CH aliph.), 781 (naph. 1,8-disubst.). ${ }^{1} \mathrm{H}$ NMR (DMSO-d $)_{6}$ (d) (ppm): 2.82-2.88 (q,2H,CH $), 6.10-6,13(\mathrm{q}, 1 \mathrm{H}, \mathrm{CH}), 7.86-7.89$ (t,2H,arom.), 8.43-8.45 (d,2H,arom.), 8.51-8.53 (d,2H,arom.), 12.49 (s,2H,OH). ${ }^{13} \mathrm{C}$ NMR $\left(\right.$ DMSO- $\left.d_{6}\right)(\mathrm{d})(\mathrm{ppm}): 34.2\left(\mathrm{CH}_{2}\right), 49.3(\mathrm{CH}), 121.5,127.2,129.1,131.1$, 132.1, 134.7 ( $\mathrm{C}$ arom.), 163.1 ( $\mathrm{C}=\mathrm{O}$ imide), 170.6, 172.1 ( $\mathrm{C}=\mathrm{O}$ acid).

DA-GI. Yield: $82 \%$. [a] ${ }_{589}^{17}(\mathrm{DMF})=-5\left(\mathrm{deg}^{-1} \mathrm{~g}^{-1} \mathrm{~cm}^{3}\right)$. M.p.: $262-264{ }^{\circ} \mathrm{C}$. IR $(\mathrm{KBr})(\mathrm{n})\left(\mathrm{cm}^{-1}\right): 3435(\mathrm{O}-\mathrm{H}), 3070(\mathrm{C}-\mathrm{H}$ arom. $), 2935$ (C-H aliph.), $1761(\mathrm{C}=\mathrm{O}$ imide), 1730 ( $\mathrm{C}=\mathrm{O}$ acid $), 1699,1649(\mathrm{C}=\mathrm{O}$ imide $), 1589,1511(\mathrm{C}=\mathrm{C}$ arom. $)$, 1438 (CH aliph.), 779 (naph. 1,8-disubst.), ${ }^{1} \mathrm{H}$ NMR (DMSO- $d_{6}$ ) (d) (ppm): 2.35-2.54 (m, $\left.4 \mathrm{H}, \mathrm{CH}_{2}-\mathrm{CH}_{2}\right)$, 5.62-5.65 (q, $\left.1 \mathrm{H}, \mathrm{CH}\right)$, 7.88-7.92 (t,2H,arom.), 8.48-8.50 (d,2H,arom.), 8.53-8.54 (d,2H,arom.). ${ }^{13} \mathrm{C}$ NMR (DMSO-d $)$ (d) (ppm): $23.6\left(\mathrm{CH}_{2} \mathrm{CH}_{2}\right), 30.5\left(\mathrm{CH}_{2} \mathrm{CO}\right), 52.5(\mathrm{CH}), 121.7,127.3,127.4,131.3$, $134.5,134.8$ ( $\mathrm{C}$ arom. $), 163.4(\mathrm{C}=\mathrm{O}$ imide $), 170.9,174.0(\mathrm{C}=\mathrm{O}$ acid $)$.

The diamine bis(4-aminophenyl)diphenylsilane was obtained according to a described procedure. ${ }^{12}$

Poly(imide-amides) (PIAs)

Poly(imide-amides) were obtaining according to the following general procedure [3]. A mixture of $5 \mathrm{mmol}$ of the diamine, $5 \mathrm{mmol}$ of the diacid, $0.24 \mathrm{~g}$ of $\mathrm{CaCl}_{2}, 0.3 \mathrm{~mL}$ of triphenylphosphite, $1.2 \mathrm{~mL}$ of pyridine and 1.8 $\mathrm{mL}$ of NMP was heated at $60{ }^{\circ} \mathrm{C}$ for one hour and then at $120^{\circ} \mathrm{C}$ for 3 hours. After this time the mixture was poured in $300 \mathrm{~mL}$ of methanol, and the solid 
was filtered, washed several times with methanol, dried under vacuum until constant weight, and characterized.

PIA-As. IR (KBr) (n) $\left(\mathrm{cm}^{-1}\right): 3424(\mathrm{~N}-\mathrm{H}), 3067$ (C-H arom.), 2939 (C-H aliph.), 1703 ( $\mathrm{C}=$ imide), 1664 ( $\mathrm{C}=\mathrm{O}$ amide), 1588, 1509 ( $\mathrm{C}=\mathrm{C}$ arom.), 1458 (CH aliph.), 845 (arom. p-subst.), 780 (naph. 1,8-disubst.), 743, 701 (arom. mono-subst.). ${ }^{1} \mathrm{H}$ NMR (DMSO- $d_{0}$ ) (d) (ppm): 2.76-2.78 (d,2 $\left.\mathrm{H}_{1} \mathrm{CH}_{2}\right), 6.27$ (t,1H,CH), 7.39-8.54 (m,24H,arom.), $9.94(\mathrm{~s}, 1 \mathrm{H}, \mathrm{NH}), 10.29(\mathrm{~s}, 1 \mathrm{H}, \mathrm{NH}) .{ }^{13} \mathrm{C}$ NMR (DMSO- $d$ ) (d) (ppm): $36.3\left(\mathrm{CH}_{2}\right), 51.0(\mathrm{CH}), 118.6,119.7,122.6$, 127.1, 127.6, 127.7, 128.0, 128.1, 130.1, 131.6, 133.9, 134.4, 135.7, $136.4(\mathrm{C}$ arom.), $163.5(\mathrm{C}=\mathrm{O}$ imide $), 167.6,169.0(\mathrm{C}=\mathrm{O}$ amide $) .{ }^{29} \mathrm{Si}$ NMR (DMSO- $\left.d_{6}\right)$ (d) (ppm): -15.33 .

PIA-Gl. IR (KBr) (n) ( $\left.\mathrm{cm}^{-1}\right): 3423(\mathrm{~N}-\mathrm{H}), 3066(\mathrm{CH}$ arom.), $2927(\mathrm{C}-\mathrm{H}$ aliph. $), 1751(\mathrm{C}=\mathrm{O}$ imide $), 1662(\mathrm{C}=\mathrm{O}$ amide $), 1588,1509(\mathrm{C}=\mathrm{C}$ arom. $)$, 1454 (CH aliph.), 844 (arom. p-subst.), 780 (naph. 1,8-subst.), 755, 701 (arom. mono-subst.). ${ }^{1} \mathrm{H}$ NMR (DMSO- $d$ ) (d) (ppm): 2.51 (m,4H,CH $), 5.73$ $(\mathrm{t}, 1 \mathrm{H}, \mathrm{CH}), 7.21-8.48$ (m,24H,arom.), $9.80(\mathrm{~s}, 1 \mathrm{H}, \mathrm{NH}), 9.91(\mathrm{~s}, 1 \mathrm{H}, \mathrm{NH}),{ }^{13} \mathrm{C}$ NMR (DMSO- $\left.d_{6}\right)(\mathrm{d})(\mathrm{ppm}): 23.4\left(\mathrm{CH}_{2} \mathrm{CH}_{2}\right), 33.1\left(\mathrm{CH}_{2} \mathrm{CO}\right), 53.9(\mathrm{CH}), 118.2$, 120.1, 127.0, 127.6, 127.8, 128.1, 128.3, 129.7, 134.3, 134.9, 135.7, 136.0, 136.5, 140.4 (C arom.), 163.7 ( $\mathrm{C}=\mathrm{O}$ imide $), 167.9,170.7(\mathrm{C}=\mathrm{O}$ amide $) .{ }^{29} \mathrm{Si}$ NMR (DMSO- $\left.d_{6}\right)(\mathrm{d})(\mathrm{ppm}):-15.41$.

\section{RESULTS AND DISCUSSION}

The 1,8-naphthalimidyl diacids DA-As and DA-Gl were obtained from 1,8-naphthalic anhydride and an excess of aspartic or glutamic acid respectively in DMF at reflux temperature according to a described procedure. ${ }^{10}$ After the elimination of the solvent, the residue was poured into diluted $\mathrm{HCl}$ and the solid diacid derivative filtered, washed with water, dried under vacuum and characterized. The results showed in the experimental part, were in agreement with the proposed structures.

IR spectra showed similar patterns (see Figure 1). Characteristic signals are the broad band at $3400 \mathrm{~cm}^{-1}$ approximately for the $\mathrm{O}-\mathrm{H}$ stretching of both acid groups, imide and carboxylic acid stretching at $1760 \mathrm{~cm}^{-1}$. On the other hand, in the ${ }^{1} \mathrm{H}$ NMR spectra it was possible to see the pattern corresponding to the aromatic hydrogens of the 1,8-naphthalene disubstituted ring: about $7.8 \mathrm{ppm}$ for the meta-hydrogens, about $8.4 \mathrm{ppm}$ for the orto-hydrogens and about $8.5 \mathrm{ppm}$ for the para-hydrogens, all of them with respect to the carbonyl groups. ${ }^{13} \mathrm{C}$ NMR results show the signals corresponding to the three kind of $\mathrm{C}=\mathrm{O}$ groups, one of the imide group and two for the magnetically nonequivalent acids. These last signals appear to lower field respect to the imide carbonyl carbon.

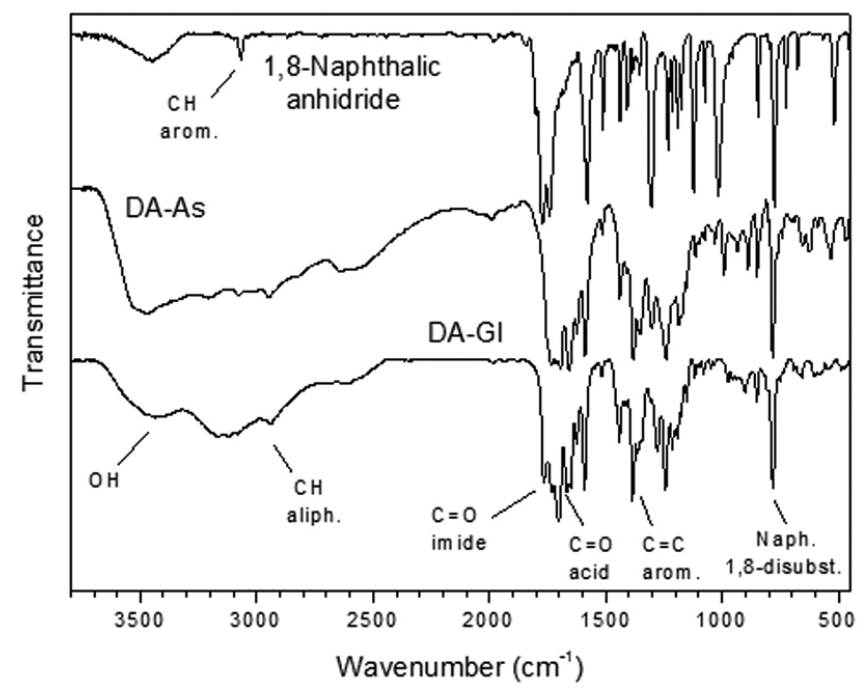

Figure 1. IR-TF spectra of DA-As, DA-Gl and the 1,8-naphthalic anhydride precursor.

PIAs were obtained from the dicarboxylic acids containing the naphthalimidyl side group (DA-As and DA-GI) and the diamine bis(4aminophenyl)dipehenylsilane according to the Yamazaki method, in which the diacid and the diamine $(1: 1 \mathrm{~mol} / \mathrm{mol})$ are mixed with triphenylphosphite, anhydrous $\mathrm{CaCl}_{2}$, pyridine and $\mathrm{NMP}^{10}$ (see Scheme 1). The mixture was vigorously stirred and heated at $120{ }^{\circ} \mathrm{C}$. Polymerization time and isolation technique were the commonly employed for these reactions. After three hours the system was poured into methanol, filtered, washed, dried under vacuum, and characterized.

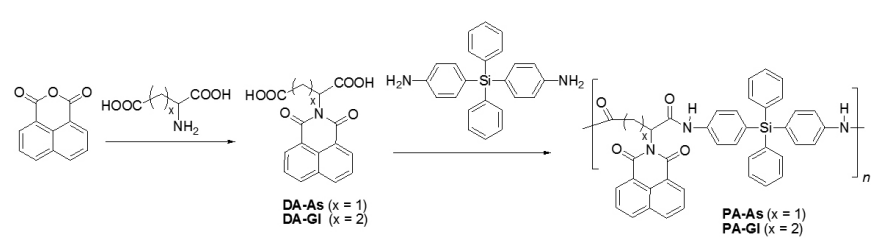

Scheme 1. Synthesis of monomers and PIAs

For both PIAs it was possible to see in the IR the replacement of the broad band corresponding to the $\mathrm{OH}$ groups of the diacids for a narrower signal attributed to the $\mathrm{N}-\mathrm{H}$ amide stretching. ${ }^{13} \mathrm{C}$ NMR spectra showed three signals corresponding to the carbonyl groups: one for the $\mathrm{C}=\mathrm{O}$ stretching of the naphthalimidyl group and two for the diamides, which are not equivalent. ${ }^{29} \mathrm{Si}$ NMR showed the signal corresponding to the $\mathrm{Si}$ atom bonded to four aromatic rings at about $-15 \mathrm{ppm}$, which has been described in previous works for silylated compounds. ${ }^{13-14}$

Table 1. Solubility of PIAs.

\begin{tabular}{lllllll}
\hline Polymer & DMSO & DMF & DMAc & NMP & $\mathrm{CHCl}_{3}$ & THF
\end{tabular}

\begin{tabular}{lllllll}
\hline PIA-As & + & + & + & + & $+/-$ & $+/-$ \\
PIA-GI & + & + & + & + & $+/-$ & $+/-$
\end{tabular}

\section{+ : soluble at room temperature, $+/-$ : soluble with heating}

Table 1 shows that the PIAs were soluble in aprotic polar solvents such as DMSO, DMF, $N, N$-dimethylacetamide (DMAc) and NMP, and soluble with heating in solvent of lower polarity $\left(\mathrm{CHCl}_{3}\right.$ and THF). Other PIAs studied by us containing the naphthalimidyl side group, were soluble only in aprotic polar solvents in spite of to have aliphatic amino acids residues in the side chain, but only aromatic groups in the main chain. ${ }^{15}$ In our case, the methylenic groups contributed by the amino acids residues, and the presence of the silicon atoms which are located in the main chain promoted an increase of the solubility in common organic solvents like $\mathrm{CHCl}_{3}$ and THF. Probably, the higher flexibility of the chains promoted by $\mathrm{sp}^{3}$ carbons and the partial polarity of the $\mathrm{C}-\mathrm{Si}$ bond due to the difference of electronegativity between these atoms, ${ }^{16}$ are the reasons that explain the obtained results. In this sense, the difference between the aminoacidic residues incorporated with one or two methylene groups, does not influence in the behaviour of PIAs.

Table 2 shows the good yields obtained for both PIAs, and the low inherent viscosity values obtained. This last parameter is indicative of the oligomeric nature of both PIAs, probably due to the insolubility of the growing chains in the reaction media. Also in this Table the values of the optical rotation obtained from DMF solution are shown, being the two PIAs of levorotatory nature, the same that the amino acids and the monomers.

Table 2. Yields, $[\mathrm{a}]_{\mathrm{D}}, \mathrm{h}_{\mathrm{inh}}$, and Tg of the PIAs.

\begin{tabular}{|c|c|c|c|c|}
\hline & Yield (\%) & {$[\alpha]_{\mathrm{D}}\left({ }^{\circ}\right)^{*}$} & $\eta_{\text {inh }}(\mathrm{dL} / \mathrm{g}) * *$ & $\operatorname{Tg}\left({ }^{\circ} \mathrm{C}\right)$ \\
\hline PIA-As & 91 & -12 & 0.12 & 163 \\
\hline PIA-GI & 97 & -30 & 0.10 & 158 \\
\hline
\end{tabular}

\footnotetext{
* In $N, N$-dimethylformamide at $25^{\circ} \mathrm{C}(\mathrm{c}=50 \mathrm{mg} / \mathrm{mL})$

** Inherent viscosity, in DMSO at $25^{\circ} \mathrm{C}(\mathrm{c}=0.3 \mathrm{~g} / \mathrm{dL})$

Table 2 also shows the Tg values of both PIAs, which were relatively high considering the aliphatic nature of the diacids moieties. Also, the bulky side naphthalimidyl group can cause a high $\mathrm{Tg}$ value due to an impediment of the rotation which can diminish the flexibility of the chain. If we consider that the acid residue is aliphatic and for this reason has some flexibility, it is possible to suppose a weak hydrogen bond interaction between the NH group of the
} 
main chain with the carbonyl one of the side group. When the length of the main chain was increased in one - $\mathrm{CH}_{2}$ - group (PIA-GI), the $\mathrm{Tg}$ value decreased due to the lower possibility of internal interaction which promotes a higher flexibility of the main chain.

Thermal decomposition temperature (TDT) values for both PIAs are summarized in Table 3. A polymer is considered as thermostable if at $400{ }^{\circ} \mathrm{C}$ the weight lost is lower than $10 \%$. In this sense, PIAs were not thermostable, however, they showed high TDT values $\left(>310^{\circ} \mathrm{C}\right)$. In particular, PIA-Gl showed a decrease of $25^{\circ} \mathrm{C}$ in relation to PIA-As due to their higher aliphatic content in the main chain. On the other hand, the residue content was similar when the samples were heated at $600{ }^{\circ} \mathrm{C}$ under $\mathrm{N}_{2}$ gas. Probably silicon oxides and similar derivatives are important components of the final mixture.

Table 3. Thermal degradation temperatures (TDT) of the PAIs

\begin{tabular}{|c|c|c|}
\hline & $\operatorname{TDT}(10 \%)^{*}\left({ }^{\circ} \mathrm{C}\right)$ & Residue** (\%) \\
\hline PIA-As & 340 & 36 \\
\hline PIA-GI & 315 & 40 \\
\hline
\end{tabular}

* Temperature at which a $10 \%$ weight loss was recorded by TG $\left(20^{\circ} \mathrm{C} /\right.$ min in nitrogen atmosphere).

** Residual weight (\%) at $600{ }^{\circ} \mathrm{C}$ (in nitrogen atmosphere).

Optical transmittance of the polymers was studied in NMP at $0.5 \mathrm{~g} / \mathrm{L}$. Table 4 shows these values for both PIAs. At $400 \mathrm{~nm}$ only PIA-As derived from aspartic acid showed high transparence in the UV-vis region. However, at $450 \mathrm{~nm}$ both PIAs showed a similar optical behavior. The high transparence of these PIAs at $450 \mathrm{~nm}$ can be explained by their aliphatic character, which implies a higher flexibility and lower molecular packing forces. The cutoff wavelength $\left(1_{\text {cutoff }}\right)$ is a value that is reported for each polymer. From that value the polymer begins to see some transparency, while below the value the material in completely opaque. In this case both PIAs showed very similar values.

Table 4. Transmittance values of the PIAs.

\begin{tabular}{cccc}
\hline Polymer & $\mathrm{T}_{400} *(\%)$ & $\mathrm{T}_{450} *(\%)$ & $\lambda_{\text {cutoff }} * *(\mathrm{~nm})$ \\
\hline PIA-As & 87 & 94 & 362 \\
PIA-GI & 20 & 91 & 361 \\
& \multicolumn{3}{|c}{} \\
\hline
\end{tabular}

\footnotetext{
* Transmittance at 400 and $450 \mathrm{~nm}$; respectively.
}

** Cutoff wavelength

\section{CONCLUSIONS}

Two optically active PIAs derived from aliphatic diacids, aspartic and glutamic, containing a bulky naphthalimidyl side group, and an aromatic diamine containing a Si atom were synthesized according to the Yamazaki method. Polymers, obtained with good yields, were of low molecular weight and probably of oligomeric nature. The Tg values were relatively high due to the volume of the side groups, but PIA-b with a more aliphatic character showed a lower value. In spite of PIAs were not thermostable according to the definition, they showed good TDT values and depending of the aliphatic character. The transparence properties of the PIAs were good but at $450 \mathrm{~nm}$, and at $400 \mathrm{~nm}$ only PIA-a derived from aspartic acid showed good transparence properties.

\section{ACKNOWLEDGEMENTS}

Authors acknowledge "Fondo Nacional de Investigación Científica y Tecnológica", FONDECYT, through Project No 1100015.

\section{REFERENCES}

1. J. Lin, D.C. Sherrington, Adv. Polym. Sci. 111, 177 (1994).

2. H.H. Yang, Aromatic High-Strength Fibers. Wiley, New York, 1989.

3. K.L. Mittal, Polyimides: Synthesis, Characterization and Applications, vol 1 and 2. Springer, New York, 1984.

4. I. Sava, M. Bruma, B. Schulz, F. Mercer, V.N. Reddy, N. Belomoina, J. Appl. Polym. Sci., 65, 1533 (1997).

5. S.H. Hsiao, C.P. Yang, K.Y. Chu, J. Polym. Sci. Part A: Polym. Chem., 35, 1469 (1997)

6. S.H. Hsiao, Y.M. Chang, J. Polym. Sci. Part A: Polym. Chem., 42, 4056 (2004).

7. D.J. Liaw, B.Y. Liaw, J.M. Tseng, J. Polym. Sci. Part A: Polym. Chem., 37, 2629 (1999).

8. S.E. Mallakpour, A. Zadehnazari, Express Polym. Lett., 5, 142 (2011).

9. C.P. Yan, J.H. Lin, J. Polym. Sci. Part A: Polym. Chem., 32, 369 (1994).

10. N. Yamazaki, M. Matsumoto, F. Higashi, J. Polym. Sci. Polym. Chem. Ed., 13, 137 (1975).

11. S. Mallakpour, M. Taghavi, Polymer, 49, 3239 (2008).

12. J.R. Pratt, W.D. Massey, F.H. Pinkerton, F. Thames, J. Org. Chem., 40:1090 (1975).

13. L.H. Tagle, C.A. Terraza, H. Villagra, A. Tundidor-Camban, Polym. Bull., 67, 1799-1807 (2011).

14. C.A. Terraza, L.H. Tagle, F. Concha, L. Poblete, Desig. Mon. Polym., 10, 253 (2007).

15. L.H. Tagle, C.A. Terraza, A. Tundidor-Camba, F.A. Lara, submitted.

16. www.webelements.com. 